\title{
Do fetichismo da organização e da tecnologia ao mimetismo tecnológico: os labirintos das fábricas recuperadas
}

\author{
Maurício Sardá de Faria \\ Dep. de Estudos e Divulgação da Secretaria Nacional de Economia \\ Solidária DED/Senaes/MTE
}

\section{Renato Dagnino}

Universidade Estadual de Campinas (Unicamp)

\author{
Henrique Tahan Novaes \\ Universidade Estadual de Campinas (Unicamp)
} Do fetichismo da organização e da tecnologia ao mimetismo tecnológico: os labirintos das fábricas
recuperadas

Resumo: Neste ensaio, examinam-se os fenômenos das fábricas recuperadas, da autogestão e das lutas sociais no capitalismo contemporâneo. Inicia-se com um breve retrospecto histórico sobre esses temas para, em seguida, situar descritivamente as empresas recuperadas. O estudo tem como foco a análise das formas variadas de controle dos trabalhadores sobre os instrumentos de trabalho, e a oportunidade que eles apresentam para a autonomização das práticas coletivas de organização da classe. Uma de suas características inovadoras é a utilização do campo dos Estudos Sociais da Ciência e da Tecnologia para a análise dessas novas 'relações sociais', formas de controle e práticas de organização. Este ensaio é uma confluência das reflexões de três pesquisadores preocupados com as experiências atuais e pretéritas dos trabalhadores, onde o coletivismo e o igualitarismo apresentam-se como bases para a autogestão da produção e da vida social.

Palavras-chave: história da autogestão, fábricas recuperadas, tecnologia, autonomia.

From the Fetishism of Organization and Technology to Technological Mimicry: the Labyrinths of Worker-Run Factories

Abstract: This paper examines the phenomenon of worker 'recovered' factories, self-management and social struggles in contemporary capitalism. It begins with a brief historical retrospect of these issues and descriptively locates the recovered companies. The study focuses on an analysis of various forms of worker control on the instruments of labor, and the opportunity that they present to make autonomous the collective practices of class organization. One of the innovative characteristics of the article is the use of the field of the Social Studies of Science and Technology to analyze these new 'social relations', forms of control and organizational practices. The essay combines the reflections of three researchers concerned with the current and previous experiences of workers, where collectivism and egalitarianism are bases for self-management of production and social life.

Key words: history of self-management, recovered factories, technology, autonomy. 


\section{Introdução}

Este estudo resulta de uma reflexão sobre os fenômenos das fábricas recuperadas, da autogestão e das lutas sociais no capitalismo contemporâneo, que tem como elemento distintivo a consideração do aspecto cognitivo, ou, mais especificamente, tecnológico, que é entendido por nós como um sério, ainda que escassamente analisado, obstáculo para o seu aprofundamento e a sua radicalização.

Centra-se, fundamentalmente, na análise das formas variadas de controle dos trabalhadores sobre as condições e as relações de trabalho, e na tendência que esse controle possibilita para a autonomização das práticas coletivas de organização da classe.

Coerentemente com nossa preocupação com o aspecto cognitivo, procuramos adicionar uma perspectiva ainda ausente na trajetória das abordagens recentes dessas novas relações sociais, formas de controle e práticas de organização: a dos Estudos Sociais da Ciência e da Tecnologia. Dessa forma, esperamos estar sugerindo caminhos para tratar de questões essenciais, ainda insuficientemente abordadas pelos estudiosos do tema: a inadequação do substrato tecnocientífico, conformado no âmbito do capitalismo, àquela tendência de autonomização das práticas coletivas de organização; e - debruçandose sobre um objeto de grande atualidade - a natureza econômica, tecnológica, social e política do fenômeno das fábricas recuperadas e dos empreendimentos com características autogestionárias.

A análise oferece uma perspectiva histórica baseada numa revisão da literatura a respeito das lutas sociais nas empresas em crise, dos problemas que envolvem a autogestão das unidades produtivas e das possibilidades que elas apresentam para a transformação do processo de produção da vida material e social. E constata que, no âmbito das fábricas recuperadas, a transformação das condições de trabalho demanda outra direção social e política, como fruto do próprio processo de auto-organização, da desalienação e da emancipação dos trabalhadores. Essa transformação, além de precisar ser realizada pelas suas próprias mãos, terá que estar baseada num substrato cognitivo alternativo ao produzido no âmbito das relações sociais tipicamente capitalistas, que emolduram as suas lutas.

\section{Um breve histórico das lutas sociais pela autonomia}

As iniciativas autogestionárias de luta e de produção dos meios de vida deixam um rastro histórico desde há pelo menos dois séculos. Neste percurso, apresentam formas institucionais e de organização variadas, submetidas às condições materiais e soci- ais da ocasião. Cenários de guerra, irrupções revolucionárias e a ascensão do capitalismo transnacional (durante os Trinta Gloriosos), crises econômicas e estruturais com respostas agressivas de corte neoliberal, são contextos onde se percebem formas de luta que enveredam pelo desenvolvimento de práticas e relações sociais novas, coletivistas e igualitaristas. Cada momento de ascensão do ciclo das lutas sociais provoca na trajetória da autogestão um movimento espasmódico e em espiral ascendente. É nossa percepção que essa trajetória traz dentro de si a possibilidade de superação das relações sociais e do modo de produção capitalistas, e, também, dos limites que aquelas conjunturas de crise encerram para o avanço social.

A recorrência de tais momentos de irrupção das práticas autônomas, como formas novas de organização dos trabalhadores, caracteriza-se pela diversidade - em termos de temporalidade e intensidade e pela sua ocorrência em espaços geográficos e nacionalidades distintas. $\mathrm{O}$ que, permite (e ao mesmo tempo obriga) uma crítica atenta às experiências autogestionárias dos dias de hoje. É urgente, para dizer de forma clara, a necessidade de que sejam observadas e rigorosamente avaliadas as potencialidades das experiências atuais no campo da economia solidária. Até que ponto elas apresentam de fato soluções novas aos antigos e conhecidos problemas do mercado, da tecnologia, da relação com o Estado que enfrentam os trabalhadores é um ponto que, ainda que de forma exploratória, procuraremos abordar mais adiante.

Nossa retrospectiva, que procura resgatar a cultura produtiva e autogestionária dos envolvidos diretamente nas experiências e a elaboração conceitual que realizam das suas práticas, ressalta como marco inicial a revolta de 1839-1842 dos tecelões de Lion, na época uma importante cidade industrial francesa. Nesse primeiro esboço contemporâneo da autogestão como forma de luta dos trabalhadores, os mestres tecelões da seda declararam que "valia mais morrer de uma bala do que de fome" e tomaram a cidade por várias semanas, cunhando a divisa "viver trabalhando ou morrer combatendo." Os canuts, como eram conhecidos, foram precursores da insígnia do "direito ao trabalho", cunhada na vaga revolucionária de 1848 (RUDE, 1982; MOISSONNIER, 1988). Durante aquela década, e para além das reivindicações objetivas, que aglutinaram os trabalhadores em torno da luta direta, o que esteve em questão foi a inserção dos operários nas unidades de produção do nascente capitalismo industrial francês. Os trabalhadores reivindicavam o direito de participar na organização dos processos de produção da vida material e social. A começar pelo seu direito de organizar seu próprio trabalho, e do direito de fazê-lo de forma distinta daquela que pregava a ideologia industrial-burguesa (MEISTER, 1972). 
Nesse período, e durante todo o Século 19, as associações e cooperativas figuraram entre as principais formas de organização e de resistência dos trabalhadores ao processo de expansão mundial do capitalismo. De fato, até a Comuna de Paris, em 1871, a associação foi o princípio articulador de relações sociais igualitárias, coletivistas e democráticas dos trabalhadores. Princípio este que se espalhou pelos vários dos países que então formavam a Europa.

Esse princípio articulador associativista assegurava, por um lado, o caráter orgânico da instituição operária e, por outro, a efetivação de laços de solidariedade com as comunidades de interesse, das quais os trabalhadores eram também agentes ativos. Por isso, ele assumiu o que, aos olhos de hoje, pode ser entendido como uma dupla função. A associação parecia 'fundir' duas funções - ou vertentes - que só posteriormente foram divididas: a organização para a produção dos meios de vida, especialmente através das diversas formas de cooperativismo (no início, principalmente, de produção, consumo e crédito); e a resistência coletiva e política à implantação do capitalismo que se imiscuía em todas as esferas da vida social.

Essas formas associativas de produção, ao substituírem a competição entre os trabalhadores pela solidariedade, e a fragmentação pelo coletivismo, revelam um processo de auto-organização que era já entendido no seu duplo aspecto de meio e de fim. A autogestão das suas lutas era compreendida pelos trabalhadores, então, como indissociável da autogestão da produção e da vida social. Por isso a pedagogia das lutas dos trabalhadores contém sempre uma dimensão organizativa, unificando os trabalhadores para a superação da exploração e do próprio assalariamento.

Neste período, a associação, como primeira forma assumida pela autogestão, era como que o princípio e o meio para a superação das relações concorrenciais e individualizantes do capitalismo no interior das unidades de produção, da sociedade, do Estado. E, também, para além das fronteiras de cada país. Não é por acaso, neste aspecto, que anos depois a primeira forma de organização internacional dos trabalhadores recebesse o nome de Associação Internacional dos Trabalhadores (BRUHAT, 1952)

A partir de então, a autogestão passou a estar presente no horizonte da luta de classes, nas organizações e nos conflitos mediante os quais os trabalhadores tentam romper com a disciplina e a fragmentação que fundamentam as relações sociais capitalistas. A proposta associativa passou a desempenhar o papel de preparar os trabalhadores para a vida coletiva, levando-os a assumir a produção das condições materiais de existência. Essa estratégia atinge um ponto culminante na Comuna de Paris (1871), quando a associação projetou-se como forma organizativa para o conjunto da sociedade, pelo menos naqueles poucos dias em que se tentou 'tomar o céu de assalto'.

A derrota da Comuna e a diáspora operária abriram o caminho para um deslocamento ideológico e político que se verificou no seio do movimento socialista internacional. Se a associação dos produtores imediatos, forjada por seus próprios meios, era a condição fundamental para a realização prática do socialismo, o massacre da Comuna e a diáspora dos socialistas franceses abriram o caminho para uma reinterpretação das tarefas prementes da classe operária e da estratégia política no interior da Segunda Internacional. A auto-organização dos trabalhadores, através do princípio associativo (cooperativo) em múltiplos campos da vida social, perde terreno e rivaliza com a tese da necessidade de organização do partido da classe operária, tendo em vista a conquista do poder político (DESROCHE, 1981)

No limiar do século 20, o desenvolvimento das estruturas e das relações sociais de produção capitalistas passou a dificultar de forma significativa a expansão do setor cooperativo de base operária. Coadjuvantes nesse processo foram a concentração de capitais, a expansão dos monopólios e a difusão das novas tecnologias e das novas técnicas de gestão ensejadas pelo capital na fabricação de mercadorias. Isto contribuiu para o abandono das práticas cooperativas e do princípio associativo, motivando seu enfraquecimento como objetivo estratégico no interior do movimento operário internacional. Passaram a ganhar terreno as formas organizativas inspiradas na social-democracia alemã no plano parlamentar e no trade-union inglês no campo da regulamentação das condições de trabalho (FARIA, 2005).

A despeito das implicações políticas dessa virada organizativa, os trabalhadores persistem na defesa das formas autônomas de organização das suas lutas no interior das unidades produtivas. Conjunturas de ruptura revolucionária ou de acirramento das contradições entre as classes possuem a capacidade de juntar, ainda que momentaneamente e com pesos diferentes, aquelas duas vertentes da prática associativa.

Diante da fuga dos patrões ou quando estes são desalojados do controle das unidades produtivas, os 
trabalhadores se vêem frente à necessidade de retomar a produção dos seus meios de vida por sua própria conta. Nada mais eficaz, quando isso ocorre, do que a ocupação das instalações, como aconteceu na Comuna de Paris, na Revolução Russa e na Guerra Civil Espanhola. E, mais recentemente, durante a greve geral de 1968 na França e nas ocupações das empresas que se seguiram até 1974; no Chile, nos três anos que durou o governo Allende; em Portugal, na Revolução dos Cravos, de 1974 a 1976; no Brasil, nas comissões de fábricas da década de 1970 e $1980^{1}$. E, na atualidade, nas fábricas recuperadas do Brasil, da Argentina, do Uruguai, da Venezuela ... ${ }^{2}$.

No Brasil, o debate sobre a autogestão e as formas autônomas de organização dos trabalhadores, merece destaque a obra de Maurício Tragtenberg, para quem a autogestão é condição essencial para a perspectiva socialista. De maneira qualificada e insistente, ele refutou tanto as teses estatizantes quanto as social-democratas. Ou seja, tanto a ditadura do partido em nome dos trabalhadores, quanto a do mercado da democracia capitalista sobre os trabalhadores. Seja qual for a situação, alertou sempre Tragtenberg para as origens da burocratização das instituições de luta, originalmente autônomas, da classe trabalhadora, como os sindicatos, as comissões, o partido (TRAGTENBERG, 1986).

No centro dos constrangimentos estruturais que levam ao estreitamento do horizonte das lutas autônomas dos trabalhadores no capitalismo, que transformam seus objetivos e funções coletivistas e igualitárias em formas assimiláveis pelo sistema, revelase a ação de um novo segmento da classe social capitalista, identificado sob noves variados, como gestores, burocratas, tecnocratas, 'ornitorrincos'....

Entender como pensa e atua esse novo segmento é crucial para avaliar a situação atual e as perspectivas da luta dos trabalhadores no interior das unidades de produção. Por seu intermédio se difunde um mecanismo de encilhamento dos horizontes das fábricas recuperadas nos limites do mercado, da tecnologia capitalista e do Estado, que por sua vez exigem e reforçam a necessidade a presença de uma categoria-função determinada. Nesses processos, um dos mecanismos centrais reside na identificação, sempre reducionista e apressada, da autogestão com a apropriação coletiva dos meios de produção pelos trabalhadores. Sugere-se, de forma mais ou menos consciente, que a modificação das relações de propriedade garanta por si só a adoção de formas autogestionárias de organização da produção, comercialização ou consumo pelos trabalhadores. E que elas poderiam assim assumir características sociais, solidárias ou socialistas, quando na verdade tendência é a de que surja um novo tipo de separação entre dirigentes e dirigidos, fracamente condicionada à propriedade dos meios de produção.
De fato, a história do movimento associativista mostra que as estruturas coletivas de gestão, criadas em conjunturas de acirramento das contradições sociais e no bojo da luta dos trabalhadores, tendem a se desarticular e desaparecer em períodos de descenso do movimento operário. Mostra, também, que a 'normalidade democrática' tende a levar a uma separação entre os que decidem sem produzir e os que produzem sem decidir acerca dos aspectos essenciais da produção, da organização e do ritmo do processo de trabalho e da tecnologia adotada ou a ser reprojetada. E que, no limite, esse processo pode levar os trabalhadores a desconhecer a própria destinação do produto do seu trabalho.

\section{Trazendo essas questões para o caso das fábricas recuperadas}

As experiências brasileiras no campo da economia solidária ganharam terreno a partir dos anos 1990, numa conjuntura defensiva do movimento dos trabalhadores. De fato, as fábricas recuperadas, cooperativas e associações de trabalhadores surgiram na contramão do intenso processo de desestruturação e precarização do trabalho, cujo ritmo passou a ser ditado pela voracidade capitalista na sua vertente neoliberal de financeirização, abertura comercial, aperto fiscal e enxugamento do Estado. Nessa conjuntura, algo que não era mais do que uma série de experiências isoladas ganha fôlego, tendo como palco as unidades produtivas em crise, especialmente as empresas familiares falidas. Surge uma perspectiva nova que apontava para a possibilidade real da propriedade coletiva dos meios de produção. Além disso, é importante destacar, essas experiências passaram a reivindicar para si (e a assumir) o sentido do associativismo e da autogestão.

Não obstante, observa-se atualmente que muitas das experiências latino-americanas no âmbito do movimento das cooperativas e das fábricas recuperadas se encontram hoje envolvidas num processo de assimilação à ordem capitalista ${ }^{3}$. Processo que possui suas origens tanto nos limites internos ao próprio movimento, como na necessidade de produzir para os circuitos de acumulação do mercado capitalista (inclusive para o mercado suntuoso das elites). Ou ainda, nos limites que decorrem das ações de um aparelho de Estado que, apesar de estar ocupado por governos simpáticos ao movimento, segue adotando políticas públicas (referentes ao crédito, às compras governamentais) cujo ajuste desfigura a dinâmica impulsionada por aqueles empreendimentos. E que tende a submetê-los às práticas usuais do mercado que favorecem o grande capital.

O que se observa é um isolamento entre os empreendimentos em autogestão. E a não-constituição de 
encadeamentos produtivos, para frente ou para trás, que permitam a essas experiências um apartamento das relações com o mercado ou, pelo menos, um 'retardamento' de sua captura pelas cadeias produtivas dominadas pelo capital. Amplifica essa tendência um quadro geral que se mantém marcado pelo avanço das forças conservadoras e das políticas de ajuste neoliberal, aplicadas vorazmente nos países periféricos, contra as quais os movimentos sociais mais não têm conseguido que impor medidas defensivas.

As imposições e restrições do Estado em relação à compra de produtos e à contratação de serviços das empresas recuperadas pelos trabalhadores, e o estímulo que oferece à aquisição de uma tecnologia convencional inadequada (embutida ou não em máquinas, equipamentos e insumos produtivos), prejudicam a sustentabilidade econômica dos empreendimentos solidários e a alteração da divisão do trabalho capitalista.

No plano técnico-administrativo interno aos empreendimentos, essas imposições dificultam a orientação autogestionária em função da tendência à sua acomodação às normas e formas usuais previstas nos manuais e reconhecidas institucionalmente. Práticas distópicas e contraproducentes (como a da elaboração de um 'plano de negócio') são freqüentemente adotadas, muitas vezes com a melhor das intenções, por ONGs e órgãos públicos.

Tudo isso faz com que, muitas vezes, o subsídio governamental especificamente destinado a esses empreendimentos (como os de catadores de material reciclável), ou proporcionado aos excluídos mediante os programas compensatórios que visam à 'inclusão social', seja apropriado como trabalho não pago pelos 'atravessadores'. E, em parte, repassado ao circuito formal de geração e apropriação de excedente da economia, o qual não consideraria atrativa a compra dos produtos desses empreendimentos caso aqueles tivessem os encargos sociais e o salário, que a legislação em vigor prevê, incorporado ao seu preço.

Aliás, nunca é demais lembrar que as áreas onde se localizam esses empreendimentos só não são ocupadas pelas empresas privadas porque sua taxa de lucro se situa bem abaixo da média da economia. É sua baixa rentabilidade que torna essas áreas passiveis de serem por eles exploradas.

No âmbito do campo denominado de economia solidária, do qual participam no Brasil a maioria das experiências de empresas recuperadas, o debate, sobre o que nos parece ser uma das questões fundamentais, o da sobrevivência dos empreendimentos com características autogestionárias e da constituição de encadeamentos produtivos que permitam seu fortalecimento, pouco tem avançado. Quando abordado, ele é frequentemente 'encerrado' com a recomendação de que esses empreendimentos devem 'modernizar-se', incorporando as novas tecnologias capazes de torná-los 'competitivos'4 Quem faz recomendações dessa natureza entende que só resta às fábricas recuperadas imitar a tecnologia (incluindo aí a organização do processo de trabalho) das empresas convencionais.

Nossa visão se contrapõe à da maioria dos partidários da economia solidária - autores com os quais temos dialogado que acreditam que a tecnologia convencional, engendrada sob a égide das relações sociais de produção capitalistas para atender à lógica de acumulação das grandes empresas, pode ser 'usada' sem significativas modificações nos empreendimentos com características autogestionárias (NOVAES, 2007b).

Se o debate sobre a economia solidária tem avançado significativamente na crítica à organização do processo de trabalho capitalista (orgware), o mesmo não ocorre em relação à tecnologia de tipo hardware. De forma geral, uma vez que aqueles autores não poderiam ser aqui melhor apresentados, cabe sintetizar sua visão dizendo que ela incorpora um elemento cognitivo (ou, mais especificamente, tecnocientífico) ainda não contemplado. Por um lado, há que se verificar em que medida as máquinas criadas num contexto capitalista, heterogestionário, com o propósito de acumular capital, podem ser 'reprojetadas' tendo em vista a produção de valores de uso, a autogestão e o desenvolvimento intelectual dos "produtores associados ' ${ }^{5}$. Adicionalmente, os pesquisadores e militantes da economia solidária parecem não perceber que o conhecimento produzido para a promoção da heterogestão não pode ser adaptado para outros fins, cabendo então a necessidade de uma nova rota de pesquisa e desenvolvimento de produtos, máquinas e processos adequados à promoção da autogestão.

A partir de uma visão crítica sobre a base cognitiva do modo de produção capitalista, temos explicado o porquê da persistência do caráter fetichizado da tecnologia nas fábricas recuperadas e, de maneira geral, nas experiências no campo da economia solidária.

Como uma forma de superar essa visão ainda dominante, formulamos a proposta da Adequação Sociotécnica (AST), que parte do reconhecimento da inadequação da tecnologia concebida e aplicada pela e para a empresa capitalista aos princípios, valores e interesses do movimento cuja trajetória aqui mostramos. Baseada nos estudos sobre aprendizagem técnico-econômica latino-americanos, e na visão de autores marxistas contemporâneos - que, revisitando o enfoque da construção social da tecnologia ${ }^{6}$, argumentam no sentido contrário às concepções da neutralidade de ciência e do determinismo tecnológico - a proposta da Adequação Sociotécnica oferece um instrumental útil para a análise e proposição de alternativas ao que temos denominado Tecnologia Convencional (DAGNINO, 2001; DAGNINO; BRANDÃO; NOVAES, 2004, NOVAES, 2007b). 
A proposta da AST busca interlocução com a corrente principal do marxismo, que ainda acredita que as forças produtivas seguem um caminho linear e inexorável e que podem ser 'usadas' para outros fins caso sejam 'apropriadas' pelos trabalhadores (DAGNINO; NOVAES, 2007). E o faz oferecendo parâmetros para a desconstrução/reconstrução de artefatos tecnológicos que são, além de adequados, indispensáveis ao crescimento e à radicalização do movimento associativista e da autogestão.

Numa dimensão situada no nível da policy, a proposta da AST é uma proposta de trabalho conjunto que fazemos à comunidade de pesquisa de esquerda, preocupada com a exclusão social, para que busque perceber e atender as demandas cognitivas que a inclusão social coloca. Para que passe a questionar a idéia de que a solução para a exclusão social dar-seá no terreno puramente político, como se não existisse também um componente tecnológico (e mesmo científico) a ser satisfeito. E para que entenda que cabe a ela, enquanto parte da comunidade de pesquisa, atender às demandas dos movimentos sociais. A proposta da AST pode facilitar a emergência no interior da comunidade de pesquisa de um segmento capaz de incorporar as demandas cognitivas dos movimentos sociais à sua agenda de pesquisa ${ }^{7}$.

Ainda nessa acepção, acreditamos que a AST, por seu caráter de 'ponte' entre a crítica das forças produtivas na sociedade capitalista e a possibilidade de desconstrução e construção da tecnologia num sentido desejado, é um estribo que os movimentos sociais poderão utilizar para 'pressionar' a comunidade científica e o governo a conformar uma nova agenda de política científica e tecnológica (DAGNINO, 2004, 2007).

Novaes (2007b), em sua pesquisa sobre oito fábricas recuperadas situadas no Brasil, na Argentina e no Uruguai, aponta que três delas apresentaram processos significativos de AST. Apesar de estarem inseridas no sistema produtor de mercadorias e tenderem a reproduzir as relações de trabalho herdadas, foi constatado que elas foram capazes de incursionar em três das sete modalidades ${ }^{8}$ de AST que nossa tipologia propõe. Essas três modalidades:

a) em software, são mudanças de natureza cultural ligadas à repartição do excedente, isto é, retiradas (antigos salários) mais próximas ou igualitárias, fundos (sobras de fim de ano) igualitários ou proporcionais, adequação parcial da fábrica aos interesses dos trabalhadores (melhoria dos refeitórios, eventos culturais na fábrica...), apropriação do conhecimento do processo produtivo sem modificação da divisão do trabalho;

b) em orgware, é a apropriação do conhecimento do processo produtivo com modificação da divisão do trabalho e c) em hardware, relacionam-se à aquisição de maquinário, às adaptações e ao repotenciamento (NOVAES, 2007b).

Ao mesmo tempo, as fábricas recuperadas observadas, embora tenham promovido processos de AST, parecem encontrar obstáculos devido:

a) à naturalização da organização do processo de trabalho pelos cooperados;

b) ao fetiche da tecnologia, que leva a que se acredite que a última tecnologia é sempre a melhor e se ignore seu caráter relacional (NOVAES; DAGNINO, 2004);

c) ao tempo necessário para uma transformação significativa das forças produtivas e da forma de repartição do excedente;

d) aos constrangimentos impostos pelo 'mercado' capitalista e

e) ao momento extremamente defensivo enfrentado pela classe trabalhadora, caracterizado pela perda de direitos trabalhistas, fragmentação das lutas e hiperexploração do trabalho (NOVAES, 2007a).

\section{Considerações finais}

Um fenômeno instigante ocorre quando os trabalhadores, na luta pelos seus interesses materiais e sociais, criam instituições novas, com sentidos antagônicos àqueles que orientam a organização do processo de trabalho e o substrato tecnológico que o impulsiona. Contrariamente ao individualismo e a fragmentação, os trabalhadores experimentam, nesses processos de luta, relações calçadas no coletivismo e na solidariedade. Desde os canuts lioneses que os trabalhadores recolocam a questão do 'direito ao trabalho’, como possibilidade de serem eles próprios os organizadores do processo de trabalho segundo seus princípios coletivamente construídos.

Em que pese o caráter cada vez mais amplo que assumem as lutas pela autogestão das unidades produtivas, é recorrente a constatação de que são ainda escassas as tentativas de reorganização cognitiva dos processos de trabalho, ou que enfrentam decisivamente o componente tecnológico herdado ou existente. Nessa medida, a comunidade de pesquisa deve se sentir provocada a desenvolver, junto com os trabalhadores das experiências de fábricas recuperadas, um novo substrato cognitivo alternativo e adequado ao desenvolvimento das relações sociais capitalistas.

Cabe, no entanto, a ressalva metodológica de que a observação das fábricas recuperadas não comporta análises maniqueístas. Deve-se mostrar os avanços e retrocessos que ocorrem no âmbito das mesmas e se referir às formas possíveis de transformação de um mesmo fenômeno. No entanto, é preciso reconhecer que embora significativa, a transforma- 
ção na forma de propriedade dos meios de produção não tem possibilitado, frequientemente, que se avance até a superação da substância da exploração e da opressão de classe que são inerentes às relações sociais de produção capitalistas.

Tanto para as fábricas recuperadas como para o conjunto de experiências de economia solidária, a questão de fundo por nós abordada é a do destino das experiências de organização coletiva e autogestionária, seja de uma fábrica, de uma cidade ou um país. Trata-se, enfim, de saber se as experiências em vigência podem constituir pontos de apoio para movimentos emancipatórios de organização da produção dos meios de vida. Se superam o trabalho assalariado, se dão forma ao trabalho consciente, livre, prazeroso, se aprofundam ou radicalizam a democracia nos locais de trabalho e na sociedade.

\section{Referências}

BERNARDO, J. A autonomia das lutas operárias. In: BRUNO, L.; SACCARDO, C. (Coord.). Organização, trabalho e tecnologia. São Paulo: Atlas, 1986.

BRUHAT, J. Histoire du mouvemente ouvrier français. Tome I - Des orígenes a la revolte des canuts. Paris: Éditions Sociales, 1952.

CRUZ, A. A diferença da igualdade. A dinâmica econômica da economia solidária em quatro cidades do mercosul. Tese (Doutorado em Economia) - Unicamp, Campinas, 2006.

DAGNINO, R. Innovación y desarollo social. Un desafio para América Latina. Redes, Buenos Aires, número especial, p. 107-153, mar. 1998.

Autogestão, adequação sócio-técnica $e$ economia solidária, 2001. Disponível em: <www.itcp. unicamp. br>. Acesso em: 10 fev. 2002.

A tecnologia social e seus desafios. In: LASSANCE JR. et al. Tecnologia social - uma estratégia para o desenvolvimento. Rio de Janeiro: Fundação Banco do Brasil, 2004. p. 90-108.

Um debate sobre a tecnociência: neutralidade da ciência e determinismo tecnológico. Campinas: Editora da Unicamp, 2007. No prelo

.; NOVAES, H. T. As forças produtivas e a transição ao socialismo: contrastando as concepções de Paul Singer e István Mészáros. Revista Organizações \& Democracia, Unesp, Marília, v. 7, p. 60-80, 2007.

.; BRANDÃO, F. C.; NOVAES, H. T. Sobre o marco analítico conceitual da tecnologia social. In: LASSANCE
JR. et al. Tecnologia social - uma estratégia para o desenvolvimento. Rio de Janeiro: Fundação Banco do Brasil, 2004.p. 15 a 64.

DESROCHE, H. Pratique coopérative et parti ouvrier (18761879).In:__. Solidatirés ouvrières. Tome I-Sociétaires et compagnons dans les associations coopératives (18311900). Paris: Les Editions Ouvrières, 1981, p. 99-123.

FAJN, G. et al. Fábricas y empresas recuperadas - protesta social, autogestión y rupturas en la subjetividad. Buenos Aires: Ediciones del Insituto Movilizador de Fondos Cooperativos, 2003.

FARIA, M. S. de. ...Se a coisa é por aí, que autogestão é essa ...? Um estudo da experiência 'autogestionária' dos trabalhadores da Makerli Calçados. Dissertação (Mestrado em Administração) - Universidade Federal de Santa Catarina (UFSC), Florianópolis, 1997.

Autogestão, cooperativa, economia solidária: avatares do trabalho e do capital. Tese (Doutorado em Sociologia Política) - UFSC, Florianópolis, 2005.

HOLZMANN, L. Operários sem patrão. Gestão cooperativa e dilemas da democracia. São Carlos: Editora da UFSCar, 2001.

MEISTER, A. Quelques aspects historiques de l'associationnisme en France. In.: ______. Vers uni sociologie des associations. Paris: Les Editions Ouvrières, 1972.p. 49-108.

MOISSONNIER, M. Les canuts: 'Vivre en travaillant ou mourir en combattant'. Paris: Messidor/Éditions Sociales, 1988.

MORENO, Y.; SANABRIA, W. Las empresas en cogestión y ocupadas em Venezuela, la lucha por el control obrero y el socialismo. Disponível em: $<$ http://freteco.elmilitante.org/ content/view/24/30/>. Acesso em: jun 2007.

NOVAES, H. T. Quando os patrões destroem máquinas: o debate em torno das forças produtivas em fábricas recuperadas argentinas e uruguaias. Revista de Ciências Sociais da Unisinos, São Leopoldo, v. 42, n. 166, jan./ jun. 2005.

A adequação sócio-técnica como insumo para a recuperação do Complexo Público de Ensino Superior e Pesquisa: avaliando a relação universidade - fábricas recuperadas no Brasil, Argentina e Venezuela. Campinas: FAPESP, 2006. Relatório de pesquisa

De tsunami a marola: uma breve história das fábricas recuperadas na América Latina. Revista Lutas \& Resistências, Londrina, n. 2, p. 84-97, 2007a 
O Fetiche da tecnologia - a experiência das fábricas recuperadas. São Paulo: Expressão Popular, 2007b.

.; DAGNINO, R. O fetiche da tecnologia. Revista Organizações \& Democracia, Marília, v. 5, n. 2, p. 189210, dez. 2004.

ODA, N. T. Gestão e trabalho em cooperativas de produção: dilemas e alternativas à participação. Dissertação (Mestrado em Engenharia) - Universidade de São Paulo (USP), Escola Politécnica, São Paulo, 2001.

RUDE, F. Les revoltes des canuts (novembre 1831 - avril 1834). Paris: Fançois Maspero, 1982.

RUGGERI, A.; MARTÍNEZ, C.; TRINCHERO, H. Las empresas recuperadas em la Argentina. Buenos Aires: Facultad de Filosofia y Letras, 2005.

TRAGTENBERG, M. Reflexões sobre socialismo. São Paulo: Moderna, 1986.

VIEITEZ, C.; DAL RI, N. Trabalho associado. Rio de Janeiro: DP\&A, 2001.

. A fábrica recuperada Zanon - Cooperativa Fasinpat. Revista Organizações \& Democracia, Marília: Editora da Unesp, n. 7, p. 183-196, 2006.

\section{Notas}

1 Para maiores detalhes sobre estes temas, ver Bernardo(1986) e Tragtenberg (1986).

2 Sobre as fábricas recuperadas na Argentina e no Uruguai, ver Ruggeri, Martíneze Trinchero. (2005), Fajnetal.(2003), Novaes (2005), Vieiteze Dal Ri(2006). Paraocaso Venezuelano, Moreno e Sanabria (2007). Para o caso brasileiro, ver também Faria (1997), Oda; Holzmann; Vieitez,Dal Ri(2001)eCruz(2006).

3 Ver, por exemplo, Faria(2005), Novaes (2005, 2007aeb).

4 Sobre os limites e a inviabilidade desta 'estratégia', ver Dagnino(1998,2002,2004).

5 Eminúmeras fábricas que estivemos, oproblema da tecnologia hardware não aparecia nem para os pesquisadores $\mathrm{e}$ raramente para os trabalhadores. Para as entidades de governo que subvencionam as fábricas recuperadas, há que 'dar' ou financiar a aquisição da tecnologia mais 'nova' do mercado.

6 AAST pode ser entendida como um processo inverso ao da construção sociotécnica, em que um artefato tecnológico sofreria um processo de desconstrução e reconstrução a partir de valores e interesses de grupos sociais relevantes, distintos daqueles que originalmente participaram de sua construção.
7 Sobre este tema, ver Dagnino, Brandão e Novaes (2004), Novaes (2006), relatório de pesquisa (em andamento) sobre a relação da universidade com as fábricas recuperadas na Argentina, Brasile Venezuela.

8 As sete modalidades são as seguintes relacionadas. 1) Uso: o simples uso da tecnologia (máquinas, equipamentos, formas de organização do processo de trabalho etc.) antes empregada (no caso de cooperativas que sucederam a empresas falidas), ou a adoção de tecnologia convencional, com a condição de que se altere a forma como se reparte o excedente gerado, é percebida como suficiente. 2) Apropriação: entendida como um processo que tem como condição a propriedade coletiva dos meios de produção (máquinas, equipamentos), ela implica uma ampliação do conhecimento, por parte do trabalhador, dos aspectos produtivos (fases de produção, cadeia produtiva...), gerenciais e de concepção dos produtos e processos, sem que exista qualquer modificação no uso concreto que deles se faz. 3) Ajuste do processo de trabalho: implica a adaptação da organização do processo trabalho à forma de propriedade coletiva dos meios de produção (pré-existentes ou convencionais), o questionamento da divisão técnica do trabalho e a adoção progressiva da autogestão. 4) Revitalização ou repotenciamento das máquinas e equipamentos: significa não só o aumento da vida útil das máquinas e equipamentos, mas também ajustes, recondicionamento e a revitalização do maquinário. Supõe ainda a fertilização das tecnologias antigas com componentes novos. 5) Alternativas tecnológicas: implica a percepção de que as modalidades anteriores, inclusive a do ajuste do processo de trabalho, não são suficientes para dar conta das demandas por AST dos empreendimentos autogestionários, sendo necessário o emprego de tecnologias alternativas à convencional. A atividade decorrente desta modalidade é a busca e seleção de tecnologias existentes. 6) Incorporação de conhecimento científico-tecnológico existente: resulta do esgotamento do processo sistemático de busca de tecnologias alternativas e na percepção de que é necessária a incorporação à produção de conhecimento científicotecnológico existente (intangível, não embutido nos meios de produção), ou o desenvolvimento, a partir dele, de novos processos produtivos ou meios de produção, para satisfazer as demandas por AST. Atividades associadas a esta modalidade são processos de inovação de tipo incremental, isolados ou em conjunto com centros de P\&D ou universidades. 7) Incorporação de conhecimento científico-tecnológico novo: resulta do esgotamento do processo de inovação incremental em função da inexistência de conhecimento suscetível de ser incorporado a processos ou meios de produção para atender às demandas por AST. Atividades associadas a esta modalidade são processos de inovação de tipo radical que tendem a demandar o concurso de centros de P\&D ou universidades e que implicam na exploração da fronteira do conhecimento. 


\section{Maurício Sardá de Faria}

Doutor em Sociologia Política pela Universidade Federal de Santa Catarina (UFSC)

Coordenador Geral de Promoção e Divulgação do Dep. de Estudos e Divulgação da Secretaria Nacional de Economia Solidária DED/SENAES/MTE

Esplanada dos Ministérios

Bloco F, sala 347

Brasília - Distrito Federal

CEP: 70059-900

\section{Renato Dagnino}

Doutor em Economia pela Universidade Estadual de Campinas (Unicamp)

Professor Titular do Depatamento de Política Científica e Tecnológica da Unicamp

\section{Henrique Tahan Novaes}

Doutorando em Política Científica e Tecnológica na Unicamp

Orientador: Renato Dagnino

\section{Unicamp - Instituto de Geociências}

Caixa Postal 6152

Rua João Pandiá Calógeras 151

Campinas - São Paulo

CEP: 13083-970 